\title{
Very High Cycle Fatigue of Ni-Based Single-Crystal Superalloys at High Temperature
}

\author{
A. CERVELlON, J. CORMIER, F. MAUGET, Z. HERVIER, and Y. NADOT
}

Very high cycle fatigue (VHCF) properties at high temperature of Ni-based single-crystal (SX) superalloys and of a directionally solidified (DS) superalloy have been investigated at $20 \mathrm{kHz}$ and a temperature of $1000{ }^{\circ} \mathrm{C}$. Under fully reversed conditions $(R=-1)$, no noticeable difference in VHCF lifetimes between all investigated alloys has been observed. Internal casting pores size is the main VHCF lifetime-controlling factor whatever the chemical composition of the alloys. Other types of microstructural defects (eutectics, carbides), if present, may act as stress concentration sites when the number of cycles exceed $10^{9}$ cycles or when porosity is absent by applying a prior hot isostatic pressing treatment. For longer tests ( $>30$ hours), oxidation also controls the main crack initiation sites leading to a mode I crack initiation from oxidized layer. Under such conditions, alloy's resistance to oxidation has a prominent role in controlling the VHCF. When creep damage is present at high ratios $(R \geq 0.8)$, creep resistance of SX/DS alloys governs VHCF lifetime. Under such high mean stress conditions, SX alloys developed to retard the initiation and creep propagation of mode I micro-cracks from pores have better VHCF lifetimes.

https://doi.org/10.1007/s11661-018-4672-6

(C) The Minerals, Metals \& Materials Society and ASM International 2018

\section{INTRODUCTION}

NiCKEL-BASED single-crystal (SX) superalloys are a class of material used for the design of high-pressure turbine blades due to their excellent mechanical properties at high temperature. During service, profiles of uncooled blades are mainly exposed to creep and low cycle fatigue damages. ${ }^{[1]}$ Damage mechanisms under such loading conditions have been well studied in the literature for Ni-based SX superalloys. ${ }^{[2,3]}$

However, other kinds of damaging loading conditions such as very high cycle fatigue (VHCF) can occur along the blade profile. ${ }^{[4]}$ The conventional blade's design is focused on $10^{7}$ cycles in this type of fatigue but few literature has focused on the VHCF regime at high temperature. $^{[5]}$ Literature is even more restricted for fatigue lives greater than $10^{8}$ cycles, which require the use of an ultrasonic fatigue machine. ${ }^{[6-8]}$ It is then essential to improve VHCF database for this class of

A. CERVELLON, J. CORMIER, F. MAUGET and Y. NADOT are with the Institut Pprime, ISAE-ENSMA, UPR CNRS 3346, Department of Physics and Mechanics of Materials, ENSMA Téléport 2, 1 avenue Clément Ader, BP40109, 86961 Futuroscope Chasseneuil Cedex, France. Contact e-mail: alice.cervellon@ensma.fr A. CERVELLON and Z. HERVIER are with Safran Helicopter Engines, Department of Materials and Expertise, avenue Joseph Szydlowski, 64511 Bordes, France.

Manuscript submitted February 28, 2018.

Article published online May 17, 2018 material and our knowledge on VHCF failure mechanisms at high temperatures.

A previous work from the authors ${ }^{[9]}$ has shown that under fully reversed conditions $(R=-1)$, casting pores are the main crack initiation sites in $\mathrm{VHCF}$ at $1000{ }^{\circ} \mathrm{C}$ in CMSX-4 alloy cast using a standard Bridgman solidification process. Microstructure degradation $\left(\gamma^{\prime}\right.$ coarsening or N-type $\gamma^{\prime}$ pre-rafting) has a minor impact on the VHCF life and rupture mechanisms. However, with the addition of a high mean stress, creep damage is the main factor limiting VHCF life at high temperature. In this configuration, microstructure degradation reduces VHCF life as creep damage is known to be dependent to the morphology of the $\gamma / \gamma^{\prime}$ microstructure. ${ }^{[10-12]}$ Therefore two main questions arise from these observations. Do other metallurgical defects (carbides, eutectics) impact the fracture mechanisms in VHCF, and, if so, how? Do the chemical composition and the resultant creep properties of Ni-based SX superalloys have an impact on the VHCF lifetime? The aim of the present study is to give answers to these two questions.

\section{MATERIALS AND EXPERIMENTAL PROCEDURE}

\section{A. Materials}

1. Microstructure and elaboration processes

CMSX-4 Ni-based SX superalloy has been taken during this study as a reference. CMSX-4 bars have been cast along the $\langle 001\rangle$ crystallographic orientation and 
solidified using a standard Bridgman process. Bars were solution heat treated step by step with a final treatment at $1321{ }^{\circ} \mathrm{C} / 2$ hours followed by a gas fan cooling. They were then heat treated at $1100{ }^{\circ} \mathrm{C} / 4$ hours and $870{ }^{\circ} \mathrm{C} /$ 20 hours to optimize the microstructure and resultant mechanical properties. Figure 1 shows the typical microstructure of CMSX-4 after such heat treatments.

Seven other Ni-based SX alloys have been tested in this study (see Table I). All SX bars have been solidified and heat treated with conditions similar to CMSX-4 ones. AM1 hot isostatic pressing (HIP), MCNG HIP, and AM1 liquid metal cooling (LMC) are the three exceptions. HIP materials have been solidified by the Bridgman process and received a subsequent HIP treatment. HIP treatment consisted of an additional heat treatment at $1310^{\circ} \mathrm{C} / 2$ hours under argon at a pressure of 1000 bar before solutionning. AM1 LMC was solidified by the LMC process. ${ }^{[13]}$

Finally, a directionally solidified (DS) Ni-based superalloy (DS200+ Hf) has also been used in this study. In this case, specimens were machined from DS200 + Hf plates cast in the $\langle 001\rangle$ direction. Specimens were machined parallel to the solidification direction in areas of the plate where the grain size in a plane perpendicular to the solidification direction is greater than $1 \mathrm{~mm}$. More information about the elaboration process and heat treatments can be found elsewhere. ${ }^{[14]}$ One has to notice that MAR-M200+ Hf SX alloy, which has been tested, is the single crystalline version of this DS alloy. The last column of Table I summarizes the main purpose of each alloy in this study to better understand the factors controlling the VHCF life at high temperature.

\section{Chemical compositions}

Chemical composition of each Ni-based superalloy tested can be found in Table II. AM1 HIP has a slightly different chemical compositions in comparison with the standard AM1 one used in this study. Unlike AM1 and AM1 LMC, AM1 HIP is not a super low-sulfur SX

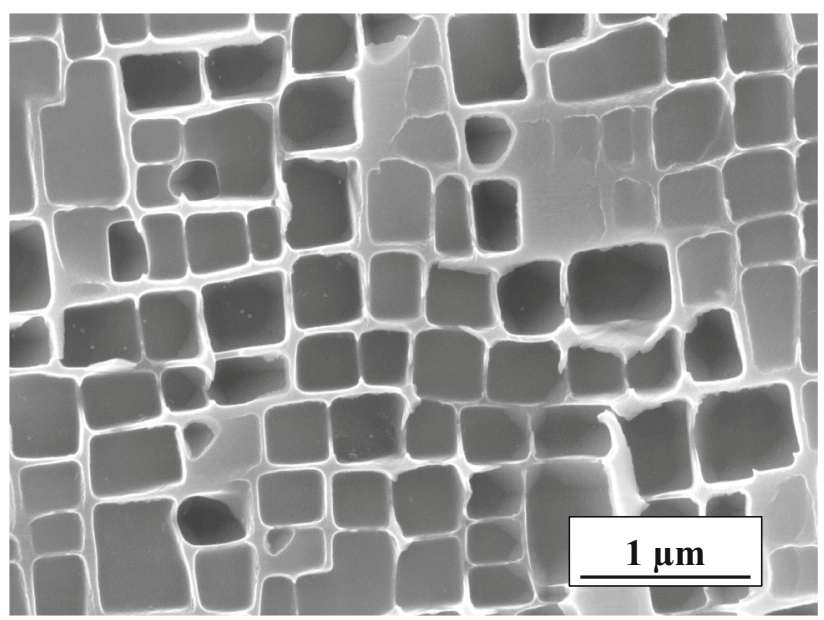

Fig. 1-CMSX-4 microstructure after solution, homogenization, and aging heat treatments $\left(\gamma^{\prime}\right.$ precipitates have been etched to reveal the microstructure). superalloy which indicates that it could have a lower oxidation resistance. ${ }^{[15]}$

MAR-M200 + Hf bars and DS200 + Hf plates were cast using ingots from the same master heat, ${ }^{[14]}$ which induces that these two alloys have the same chemical composition.

\section{Casting defects and chemical heterogeneities}

Processing of Ni-based SX and DS superalloys induces casting pores that can limit mechanical properties, especially fatigue ones. ${ }^{[18-21]}$ One aim of this study was to investigate the impact of the pore size on the VHCF properties using three AM1 and two MCNG materials processed differently. Table I presents the size range of the casting pores that acted as crack initiation sites for these alloys, and also for the other ones. Pore size is defined by the surrounding diameter method ${ }^{[21]}$ and was directly measured on the fracture surfaces.

Moreover, chemical composition of the superalloys, as well as the prior solution heat treatments, can leave the alloys with potential defects as eutectics and carbides. ${ }^{[22]}$ First results in VHCF at high temperature on Ni-based SX alloys have shown the predominant role of pores, ${ }^{[9]}$ and also carbides ${ }^{[7]}$ and eutectics on crack initiation for lifetimes in excess of $10^{9}$ cycles ${ }^{[9]}$ However, no material containing both defects have been studied, and the role of eutectics is still not clearly understood. To better understand the role of these inclusions, two sub-groups of SX alloys have been tested to investigate the impact of eutectics and carbides on the VHCF life. Eutectics have been studied via the AM1, CMSX-4, and CMSX-4 plus materials [see Figure 2(a)]. Area fraction values of eutectics for each SX superalloy are, respectively, $<0.5,<0.4$, and $\sim 1.6$ pct. The area fraction has been determined by means of area fraction measurements using four scanning electron microscope (SEM) pictures taken at a 100 times magnification. The impact of carbides has been studied by testing MAR-M200 + Hf and DS200 + Hf. Both alloys present carbides enriched in hafnium, niobium, and titanium (see Figure 2(b)). ${ }^{[23]}$ They also present eutectics but their role has been considered negligible in comparison with carbides and pores.

Table I summarizes for each Ni-based superalloy tested the initiation pore size range, others defects, the testing ratio, and finally, the purpose of their use in this study. In this table, eutectics are considered as "residual" when their area fraction does not exceed 0.4 pct in the material.

\section{B. Pre-oxidized Specimens}

Three CMSX-4 specimens were pre-oxidized to study the impact of the oxide layer on the crack initiation mechanisms and VHCF lifetime. Specimens were machined from CMSX-4 bars and polished up to a mirror finish to prevent undesirable recrystallization from machining during the thermal exposure. Then, pre-oxidation was done in a Nabertherm furnace at $1000{ }^{\circ} \mathrm{C}$ with a $\pm 2{ }^{\circ} \mathrm{C}$ temperature accuracy during 15 , 50 and 100 hours. All pre-oxidized specimens have been tested under the same condition $(R=-1$, 
Table I. Summary of SX and DS Ni-Based Superalloys Investigated During This Study

\begin{tabular}{|c|c|c|c|c|}
\hline Ni-Based Superalloy & $\begin{array}{c}\text { Size of Pores Acting as Crack } \\
\text { Initiation Site }(\mu \mathrm{m})\end{array}$ & Other Defects & Stress Ratio & Aim Study \\
\hline CMSX-4 & 50 to 150 & eutectics (residual) & $R=-1,0.8$ & $\begin{array}{l}\text { defect nature } \\
\text { creep damage }\end{array}$ \\
\hline CMSX-4 plus & 60 to 100 & eutectics & $R=-1,0.8$ & $\begin{array}{l}\text { defect nature } \\
\text { creep damage }\end{array}$ \\
\hline AM1 & 50 to 300 & eutectics & $R=-1$ & defect size \\
\hline AM1 LMC & 20 to 40 & eutectics & $R=-1$ & defect size \\
\hline AM1 HIP & - & eutectics & $R=-1$ & defect size \\
\hline $\mathrm{MCNG}$ & 50 to 150 & eutectics (residual) & $R=-1$ & defect size \\
\hline MCNG HIP & - & eutectics (residual) & $R=-1$ & defect size \\
\hline MAR-M200 + Hf & 60 to 90 & eutectics + carbides & $R=-1$ & defect nature \\
\hline $\mathrm{DS} 200+\mathrm{Hf}$ & 60 to 90 & eutectics + carbides "grain boundaries" & $R=-1,0.8$ & $\begin{array}{l}\text { defect nature } \\
\text { creep damage }\end{array}$ \\
\hline
\end{tabular}

Table II. Chemical Composition of SX and DS Superalloys Tested in Wt Pct, Bal. Ni

\begin{tabular}{|c|c|c|c|c|c|c|c|c|c|c|c|c|c|c|c|}
\hline Alloys & $\mathrm{Cr}$ & $\mathrm{Co}$ & Mo & $\mathrm{W}$ & $\mathrm{Al}$ & $\mathrm{Ti}$ & $\mathrm{Ta}$ & $\mathrm{Re}$ & $\mathrm{Ru}$ & $\mathrm{Nb}$ & Hf & $\mathrm{B}$ & $\mathrm{Fe}$ & $\mathrm{C}$ & $\mathrm{Zr}$ \\
\hline AM1 & 7.5 & 6.6 & 2 & 5.5 & 5.2 & 1.2 & 7.9 & & & & 0.04 & & & & \\
\hline AM1 (HIP) & 7.3 & 6.4 & 2 & 5.5 & 5.4 & 1.2 & 7.7 & & & & 0.01 & & & & \\
\hline CMSX-4 & 6.5 & 9.6 & 0.6 & 0.4 & 5.5 & 1.0 & 6.4 & 2.9 & & & $0.1^{*}$ & & & & \\
\hline CMSX-4 plus ${ }^{[16]}$ & 3.5 & 10 & 0.6 & 6.0 & 5.7 & 0.85 & 8.0 & 4.8 & & & 0.1 & & & & \\
\hline $\mathrm{MCNG}^{[17]}$ & 4.0 & & 1.0 & 5.0 & 6.0 & 0.5 & 5.0 & 4.0 & 4.0 & & 0.1 & & & & \\
\hline MAR-M200 + $\mathrm{Hf}^{[14]}$ & 8.6 & 9.5 & & 11.8 & 4.9 & 1.87 & & & & 0.86 & 1.58 & 0.015 & 0.02 & 0.13 & 0.01 \\
\hline $\mathrm{DS} 200+\mathrm{Hf}^{[14]}$ & 8.6 & 9.5 & & 11.8 & 4.9 & 1.87 & & & & 0.86 & 1.58 & 0.015 & 0.02 & 0.13 & 0.01 \\
\hline
\end{tabular}

*In ppm.

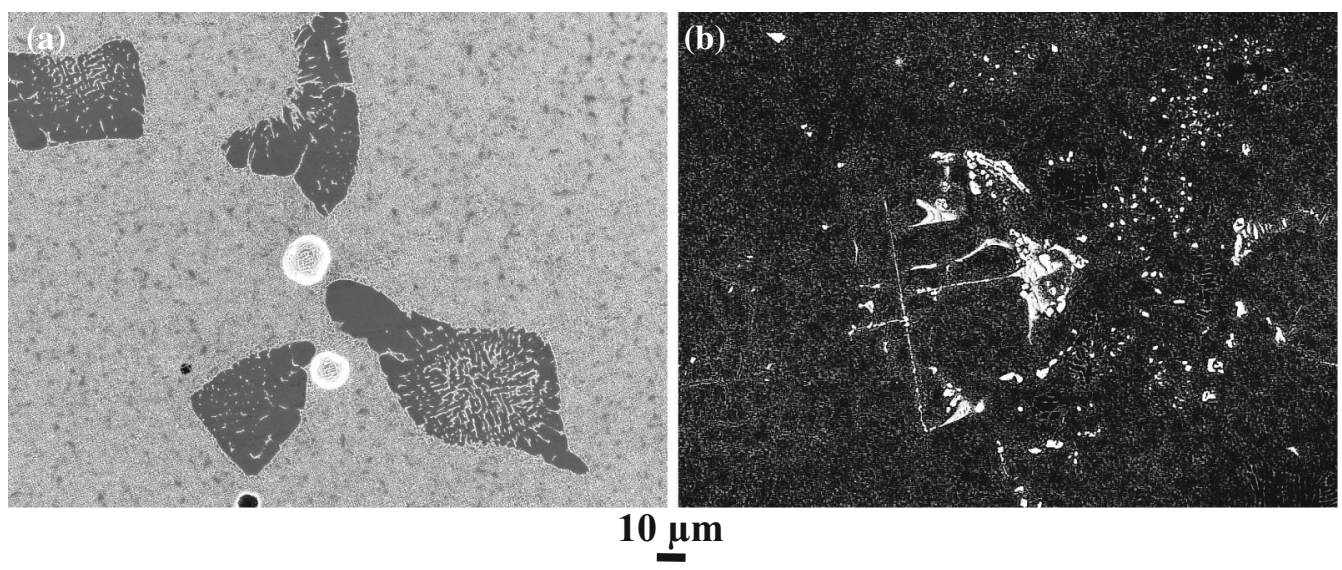

Fig. 2-Eutectics pools in CMSX-4 plus SX alloy (a). Carbides in MAR-M200 + Hf and DS200 + Hf alloys. These carbides are enriched in Hf, $\mathrm{Nb}$, and Ti (BSE mode) $(b)$.

$\left.\sigma_{\mathrm{a}}=160 \mathrm{MPa}\right)$ and have been compared with a reference CMSX-4 specimen.

\section{Fatigue Tests}

VHCF tests have been carried out using an ultrasonic fatigue machine working in the $20 \pm 0.5 \mathrm{kHz}$ frequency range. All tests have been performed in air at a temperature of $1000{ }^{\circ} \mathrm{C}$. The machine working principle can be found in the literature. ${ }^{[24-27]}$ A detailed description of the experimental procedure used during this study can be found in a previous work from the authors. ${ }^{[9]}$ Briefly, a continuous excitation is applied on the specimen to solicit at a strain ratio of $R=-1$. Over self-heating of the specimen is avoided using a closed-loop control of the specimen's temperature in the 


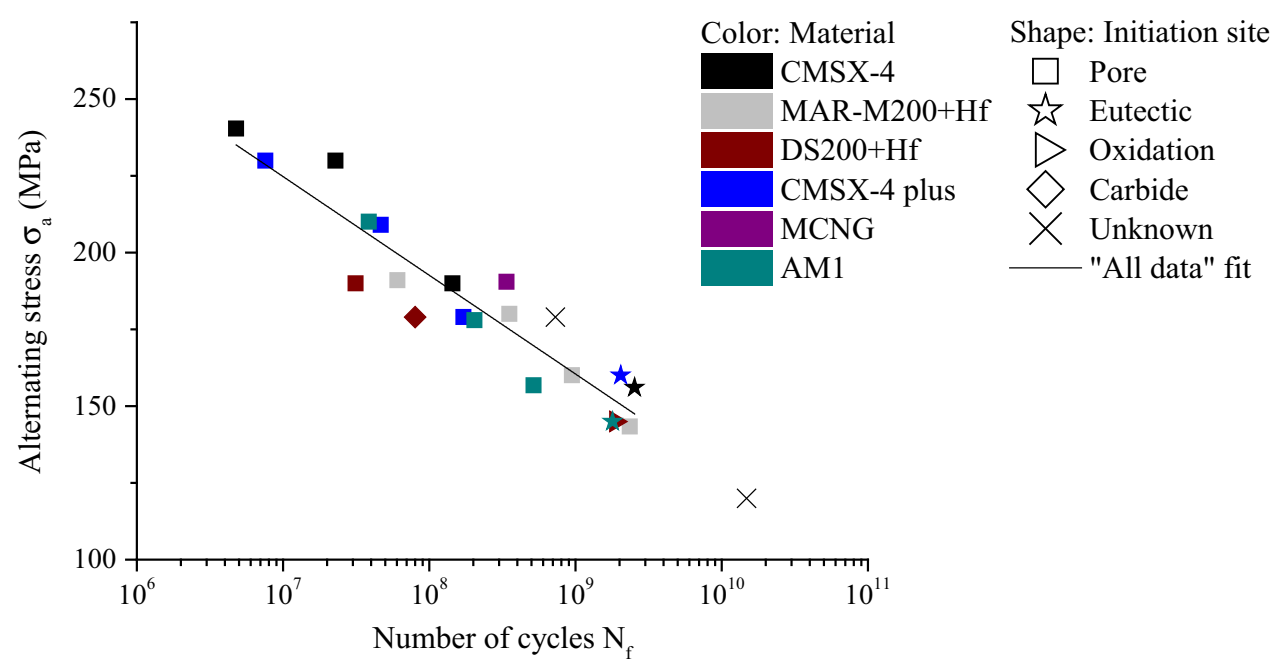

(a)

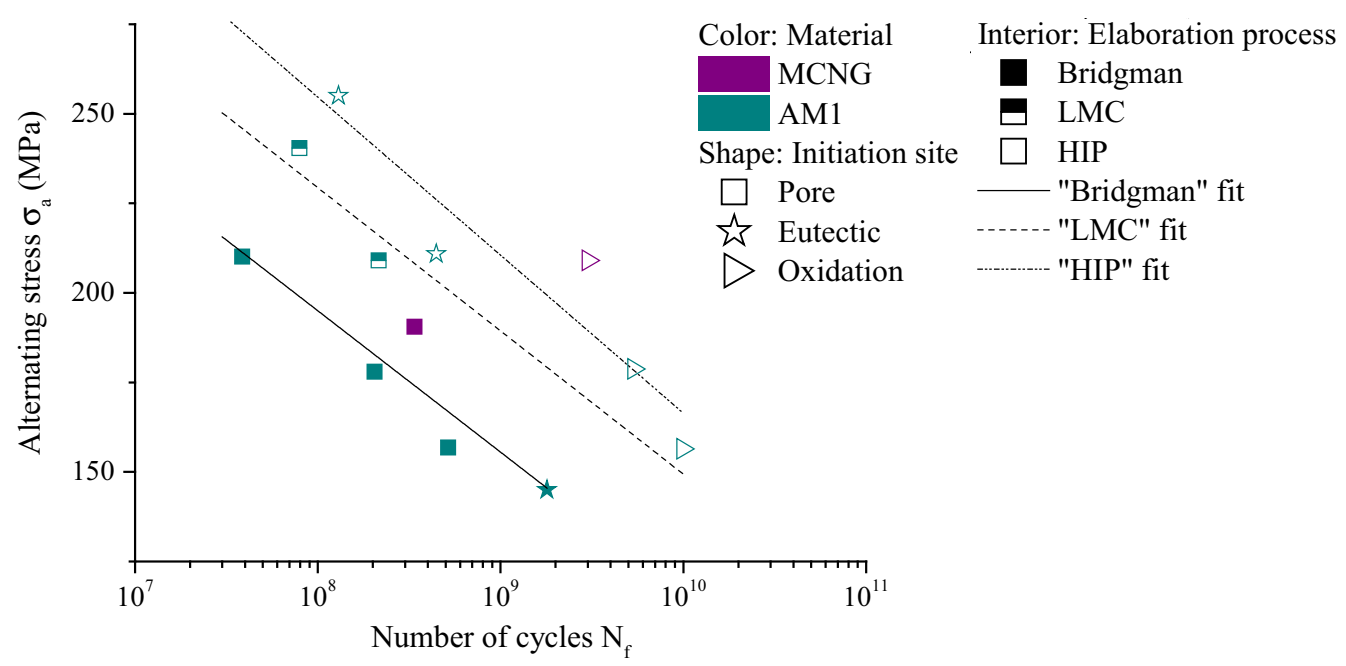

(b)

Fig. 3-S-N diagrams at $20 \mathrm{kHz}, 1000{ }^{\circ} \mathrm{C}$, and $R=-1$ : data from Bridgman materials only (a); data from AM1 and MCNG elaborated with different processes $(b)$ (Color figure online).

middle of its gage length. To carry out tests with an additional mean stress $(R>0)$, a constant load is applied on a displacement node with a pneumatic device.

Specimens have been designed so that their first tension mode frequency is of $20 \pm 0.5 \mathrm{kHz}$. Specimen dimensions have been determined previously ${ }^{[9]}$ for tests done using CMSX-4 material at $1000{ }^{\circ} \mathrm{C}$. Since at this temperature, the Young's modulus between different $\langle 001\rangle$ SX and DS superalloys is similar according to literature, ${ }^{[28-33]}$ a same geometry of specimen has been used during this study, whatever the alloy.

\section{Post-mortem Observations}

Fractographic observations (crack initiation sites and rupture modes) have been performed for each specimen failed using a JEOL JSM 6400 SEM. Secondary (SEI) and backscattered (BSE) electron imaging modes were used.
Longitudinal sections have also been performed on some specimens to analyze damage mechanisms and $\gamma / \gamma^{\prime}$ microstructure evolutions. After sectioning, these specimens have been mechanically polished up to a mirror finish until intercepting the main crack initiation site. Then, they were etched using a solution made of $1 / 3$ $\mathrm{HNO}_{3}$ and $2 / 3 \mathrm{HCl}$ (vol pct). Observations were performed using a JEOL JSM $7000 \mathrm{~F}$ field emission gun-SEM in both modes (SEI and BSE). All observations have been performed using an acceleration voltage of $25 \mathrm{kV}$.

\section{RESULTS}

A. VHCF Lifetime at Ratio of $R=-1$ and Resultant Rupture Modes

Figure 3 presents VHCF lifetimes for each alloy tested at $R=-1,1000{ }^{\circ} \mathrm{C}$, and $20 \mathrm{kHz}$. Considering 
the important volume of information, it has been decided to divide the data into two $\mathrm{S}-\mathrm{N}$ diagrams. The first one, shown in Figure 3(a), considers only the SX and DS alloys that have been elaborated by the Bridgman process. The second one, shown in Figure 3(b), plots the SX that have been elaborated with different processes (Bridgman, LMC, and HIP), i.e., MCNG and AM1 materials. For each diagram, the alternating stress $\sigma_{\mathrm{a}}(\Delta \sigma / 2)$ is plotted as a function of the number of cycles until failure $N_{\mathrm{f}}$. Different colors have been used to identify each material and different symbol shapes have been used to account for the nature of the crack initiation site.

According to Figure 3(a), no relevant difference in VHCF lifetimes under these conditions is observed between SX and DS alloys, except for LMC- and HIP-processed materials [see Figure 3(b)]. VHCF life is similar between all Bridgman cast alloys, whereas AM1 LMC and HIPped AM1 as well as HIPped MCNG show increased fatigue life by a factor 10 and 20, respectively.

When casting pores are present, crack initiation always occurs from a single and internal pore in the lifetime range of $10^{6}$ to $10^{9}$ cycles [see rectangles in Figure 3(a)]. These results are in agreement with previous results from the authors using the same experimental conditions on CMSX-4 material. ${ }^{[9]}$ In the specific case of MAR-M200+ Hf and DS200 + Hf alloys, small cracked carbides are present inside casting pores serving as crack initiation sites. Dimension ranges of casting pores that acted as crack initiation site can be found in Table I. Pore dimension ranges are similar in Bridgman SX and DS alloys [see example of pore in Figure 4(a)]. In AM1 LMC, however, crack initiation pores have a smaller size [see Table I and example in Figure 4(b)]. When no porosity is present, initiation comes from internal sites thought to be remaining eutectics in the lifetime range of $10^{6}$ to $10^{9}$ cycles. Figure 4(c) shows an example of this type of crack initiation site, which is difficult to analyze due to surface roughness in comparison with observations from past literature at $593{ }^{\circ} \mathrm{C}$ and $20 \mathrm{~Hz}^{[34]}$ This rough area, also visible in Figure 4(a) and less obviously in Figure 4(b), could be assimilated to the fine granular area (FGA, also called optical dark area) observed during $\mathrm{VHCF}$ tests at $R=-1$ that exceed $10^{7}$ cycles on high-strength steels ${ }^{[35,36]}$ and a titanium alloy. ${ }^{[37]}$ In polycrystalline alloys, the FGA is generally defined by a rough area with a grain refinement. In this study, a rough area around the internal crack initiation site has been observed for all SX and DS alloys between $10^{7}$ and $\sim 10^{9}$ cycles. The characterization of the assimilated FGA and her formation is not the aim of this paper, and will be presented in a forthcoming paper.

When failure exceeds $10^{9}$ cycles, casting pores do not act anymore as concentration sites and crack initiation switches to other metallurgical defects [see Figure 3(a)]. Initiation from a eutectic has been observed in CMSX-4, AM1, and CMSX-4 plus specimens. For MAR200+ Hf alloy, no transition from pores to another defect has been noticed, whereas DS200 + Hf initiated in one case from a cluster of carbides. When failure occurs after $10^{9}$ cycles in the DS200 + Hf alloy (26 hours of test), rupture comes from a crack that propagated in mode I from the oxide layer and intercepted a grain boundary. This type of crack initiation from the oxide layer has also been observed in AM1 HIP [see Figures 5(a) and (b)] and MCNG HIP for longer tests (at least 70 and 41 hours, respectively). Longitudinal cut has been realized on AM1 HIP specimen that has been tested at $\sigma_{\mathrm{a}}=178 \mathrm{MPa}$ and failed after 41 hours of test. Several mode I cracks that have propagated from the oxide layer $(\sim 10 \mu \mathrm{m}$ depth) are observed with a length that can approach $120 \mu \mathrm{m}$ [see Figures 5(b) and (c)]. At a blunted crack tip due to oxidation, a newly formed very small crack propagating in the matrix can be observed [see Figures 5(c) and (d)]. This very short crack is also characterized by the presence of slip bands ahead of the crack tip [see arrows in Figure 5(d)], indicating that a highly localized deformation is happening.

Previous work have shown that in CMSX-4 alloy, initiation occurs at internal defects for VHCF lives up to $10^{9}$ cycles, whereas mode I cracks whose propagation is assisted by oxidation with a length similar to pore size are present. ${ }^{[9]}$ At long lifetimes, a competition appears between internal and surface initiations. Pre-exposed CMSX-4 specimens were used to exacerbate the impact of oxidation and accelerate mode I crack initiation from
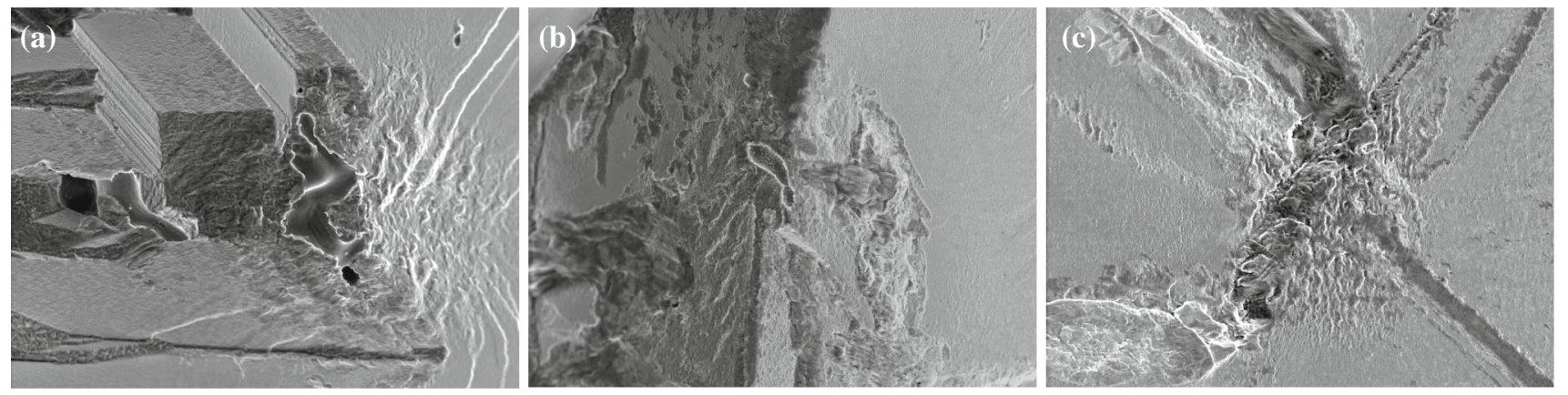

$50 \mu \mathrm{m}$

Fig. 4-Main crack initiation sites in: AM1 Bridgman (pore) tested at $\sigma_{\mathrm{a}}=178 \mathrm{MPa}$ and failed at $N_{\mathrm{f}}=2.04 \times 10^{8}$ cycles $(a)$; AM1 LMC (pore) tested at $\sigma_{\mathrm{a}}=240 \mathrm{MPa}$ and failed at $N_{\mathrm{f}}=7.9 \times 10^{7}$ cycles $(b)$; and AM1 HIP (eutectic) tested at $\sigma_{\mathrm{a}}=255 \mathrm{MPa}$ and failed at $N_{\mathrm{f}}=1.3 \times 10^{8}(\mathrm{c})$. 

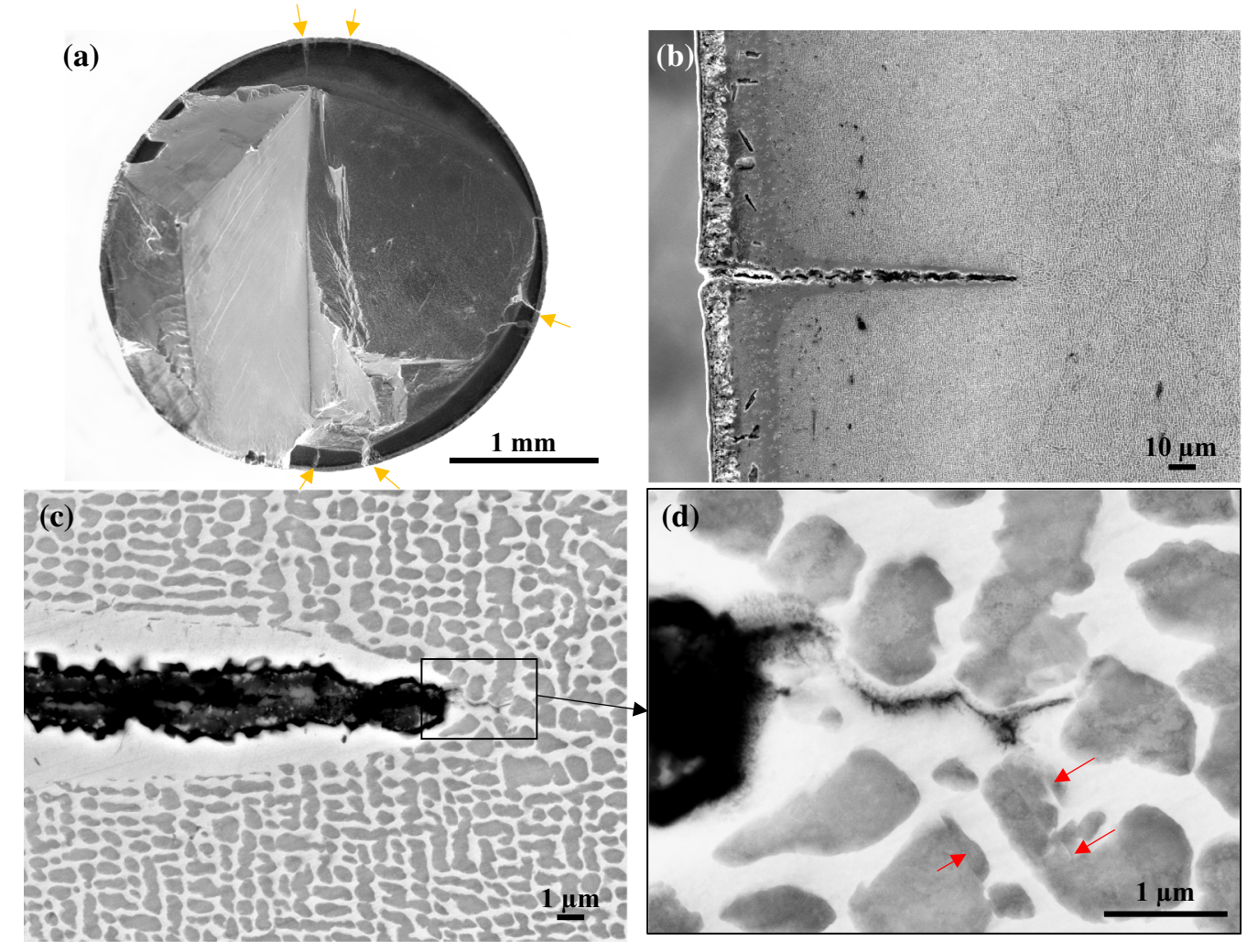

Fig. 5-Rupture surface of AM1 HIP specimen tested at $\sigma_{\mathrm{a}}=190 \mathrm{MPa}$ and failed at $N_{\mathrm{f}}=5.3 \times 10^{9}$ cycles $(a)$. Longitudinal section of AM1 HIP specimen shown in (a); propagation of mode I crack from the oxide layer (b); magnification of the crack tip (BSE mode) (c); observation of slip bands at the crack tip (BSE mode) $(d)$.

the surface. Results from pre-oxidized CMSX-4 specimens are shown in Table III. The oxide layer depth and the maximal length of cracks starting from the surface have been measured on longitudinal cuts done on each specimen after testing.

100 Hours of pre-exposition have not been sufficient to switch from an internal to a surface crack initiation mode. Initiation on each pre-oxidized specimen comes from a large casting pore, explaining the reduced $\mathrm{VHCF}$ lifetimes in comparison with the reference specimen that initiated from a eutectic.

Surprisingly, the oxide layer depth and oxidation cracks lengths are smaller than in the reference specimen. The number of cracks observed that have initiated from the surface are also lower in the pre-oxidized specimens. These observations will be further discussed in the Section IV.

Considering the final rupture and crack propagation modes, all tested alloys propagate in a crystallographic mode [see example of CMSX-4 plus and MAR-M200 + Hf in Figures 6(a) and (b)] as it was already observed using SX alloys at $20 \mathrm{kHz}$ at 593 and $1000{ }^{\circ} \mathrm{C} .{ }^{[6,7,9]}$ Two exceptions have been noticed. The first one is obtained for specimens developing crack initiation from the oxide layer [see right triangles on Figures 3(a) and (b)]. Both rupture modes (mode I and crystallographic) are observed in that case on the failure surfaces, as it is presented in Figure 5(a) on AM1 HIP.
The second exception appears in MAR-M200+ Hf and its DS version for fatigue lives in excess of $10^{8}$ cycles. Figure 6(c) shows that at the beginning of the propagation phase, the principal crack follows crystallographic plans before switching to mode I when the crack reach the surface.

\section{B. VHCF Lifetime at $R=0.8$ and Rupture Mode}

Figure 7 presents lifetimes for CMSX-4, CMSX-4 plus, and DS200 $+\mathrm{Hf}$ alloys tested at $R=0.8,1000{ }^{\circ} \mathrm{C}$, and $20 \mathrm{kHz}$. The maximum stress $\sigma_{\max }$ is plotted as a function of the number of cycles until failure $N_{\mathrm{f}}$.

At $R=0.8$, CMSX-4 plus has increased lifetimes in comparison to CMSX-4 and DS200+ Hf. With the addition of a high mean stress, the cause of failure originates from creep damage for all materials tested. In CMSX-4 and CMSX-4 plus specimens, fracture surfaces are similar with several pores that have micro-propagated in mode $I,{ }^{[9]}$ typical of creep damage [see Figures 8(a) and (b)]. Final failure is caused by a principal crack that propagates following octahedral plans from these mode I micro-cracks.

In DS200 + Hf, which has the lowest VHCF life under $R=0.8$, micro-cracks nucleate from cluster of cracked carbides [see Figures 8(c) and (d)]. Less frequently, some micro-cracked pores are also visible. 
Table III. VHCF Results on CMSX-4 Pre-oxidized Specimens Tested at $\sigma_{\mathrm{a}}=160 \mathrm{MPa}$

\begin{tabular}{lcccccc}
\hline $\begin{array}{l}\text { Exposure at } \\
1000^{\circ} \mathrm{C}(\mathrm{h})\end{array}$ & $\begin{array}{c}\text { Oxide Layer } \\
\text { Depth }(\mu \mathrm{m})\end{array}$ & $\begin{array}{c}\text { Maximal Depth of } \\
\text { Surface Cracks }(\mu \mathrm{m})\end{array}$ & $\begin{array}{c}\text { Number of Cycles } \\
\text { Until Failure }\end{array}$ & $\begin{array}{c}\text { Initiation } \\
\text { Site }\end{array}$ & $\begin{array}{c}\text { Pore } \\
\text { Size } \\
(\mu \mathrm{m})\end{array}$ & $\begin{array}{c}\text { Distance of Crack Initiation } \\
\text { Site from Surface }(\mu \mathrm{m})\end{array}$ \\
\hline 0 & 5 to 15 & 80 & $2.54 \times 10^{9}$ & eutectic & $\mathrm{X}$ & 190 to 330 \\
15 & 5 & $\mathrm{X}$ & $1.40 \times 10^{9}$ & pore & 84 & 140 \\
50 & 3 & $\mathrm{X}$ & $1.72 \times 10^{9}$ & pore & 97 & 980 \\
100 & 5 & $\mathrm{X}$ & $1.15 \times 10^{9}$ & pore & 116 & 230 \\
\hline
\end{tabular}
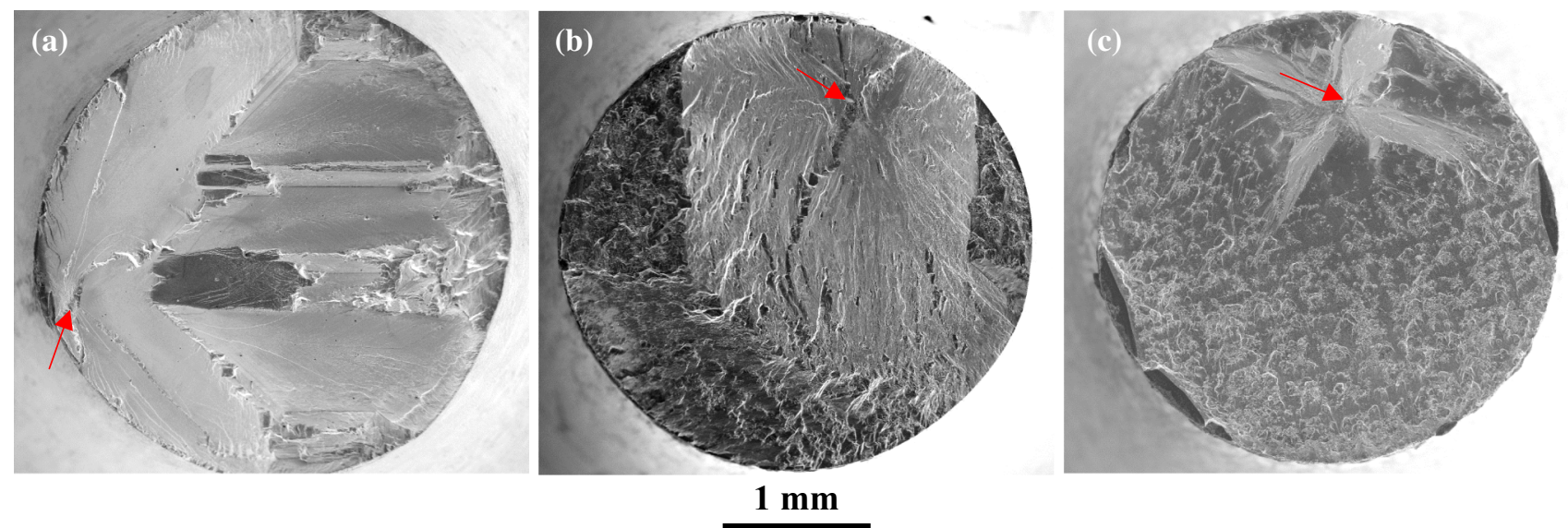

Fig. 6-Fractographic observations showing crystallographic rupture surface of CMSX-4 plus specimen tested at $\sigma_{\mathrm{a}}=180 \mathrm{MPa}$ and failed at $N_{\mathrm{f}}=1.72 \times 10^{8}$ cycles $(a)$; crystallographic rupture surface of MAR-M200 + Hf specimen tested at $\sigma_{\mathrm{a}}=190 \mathrm{MPa}$ and failed at $N_{\mathrm{f}}=6 \times 10^{7}$ cycles (b); crystallographic + mode I rupture for MAR-M200+ Hf specimen tested at $\sigma_{\mathrm{a}}=180 \mathrm{MPa}$ and failed at $N_{\mathrm{f}}=3.5 \times 10^{8}$ cycles $(c)$. Note that the first steps of crack propagation in (c) are in the crystallographic mode, and then switch to mode I.

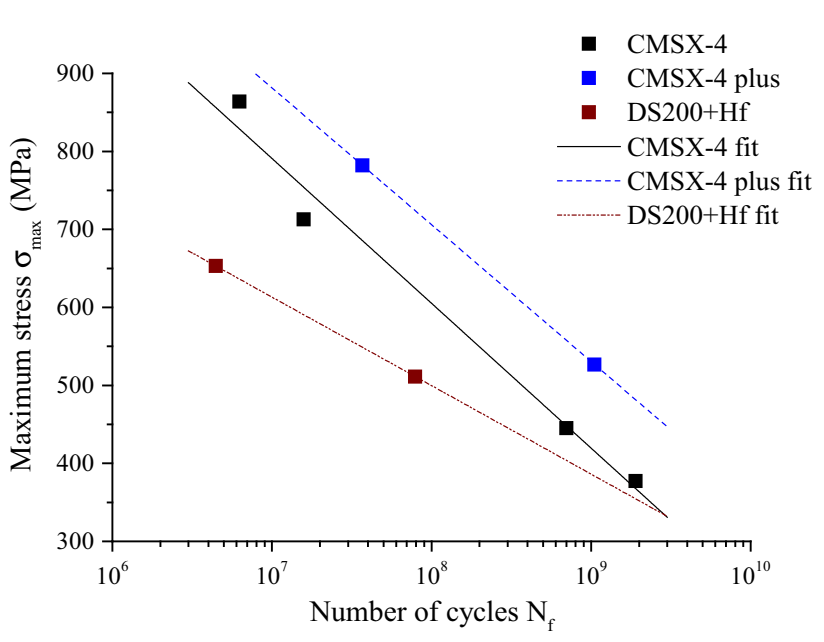

Fig. 7-S-N diagram at $20 \mathrm{kHz}, 1000^{\circ} \mathrm{C}$, and $R=0.8$.

\section{DISCUSSION}

Results of the previous section show that, depending on the dominant crack initiation and first stages of propagation mechanisms (pure fatigue, creep, and oxidation), Ni-based SX/DS superalloys do not have the same behavior or fatigue lifetimes. The first part of the Section IV will be focused on the impact of the casting process and prior heat treatments on the lifetimes during pure fatigue. These sections consider the pore size dependence and the impact of other microstructural features. Then, oxidation damage during gigacycle fatigue regime will be discussed. Finally, the consequences of creep damage in VHCF lifetime are presented.

\section{A. Pore Size Dependence at $R=-1$}

Results presented in Section III-A have shown the predominant role of the solidification process on the VHCF lifetime at $R=-1,20 \mathrm{kHz}$ and temperature of $1000{ }^{\circ} \mathrm{C}$. In the lifetime range of $10^{6}$ to $10^{9}$ cycles and for all SX and DS alloys tested (except HIP ones), fatal cracks initiate from a casting pore. This is in agreement with VHCF results obtained at room temperature on $\mathrm{SX}^{[38]}$ and DS alloys. ${ }^{[39]}$ It appears that the smaller the pore size is, the higher the VHCF life [see Figure 3(b) focused on AM1 and MCNG alloys], which is in agreement with previous studies done in the $\operatorname{LCF}^{[18,20,21]}$ and $\operatorname{HCF}^{[18,19]}$ regimes when environment has (almost) no impact. Since the casting pore size in the specimen volume (and more specifically, the tail of the pore size distribution toward larger sizes) is directly connected to the solidification process, ${ }^{[22]}$ then the LMC solidification process shows a high improvement in the VHCF life in comparison to the Bridgman one. 

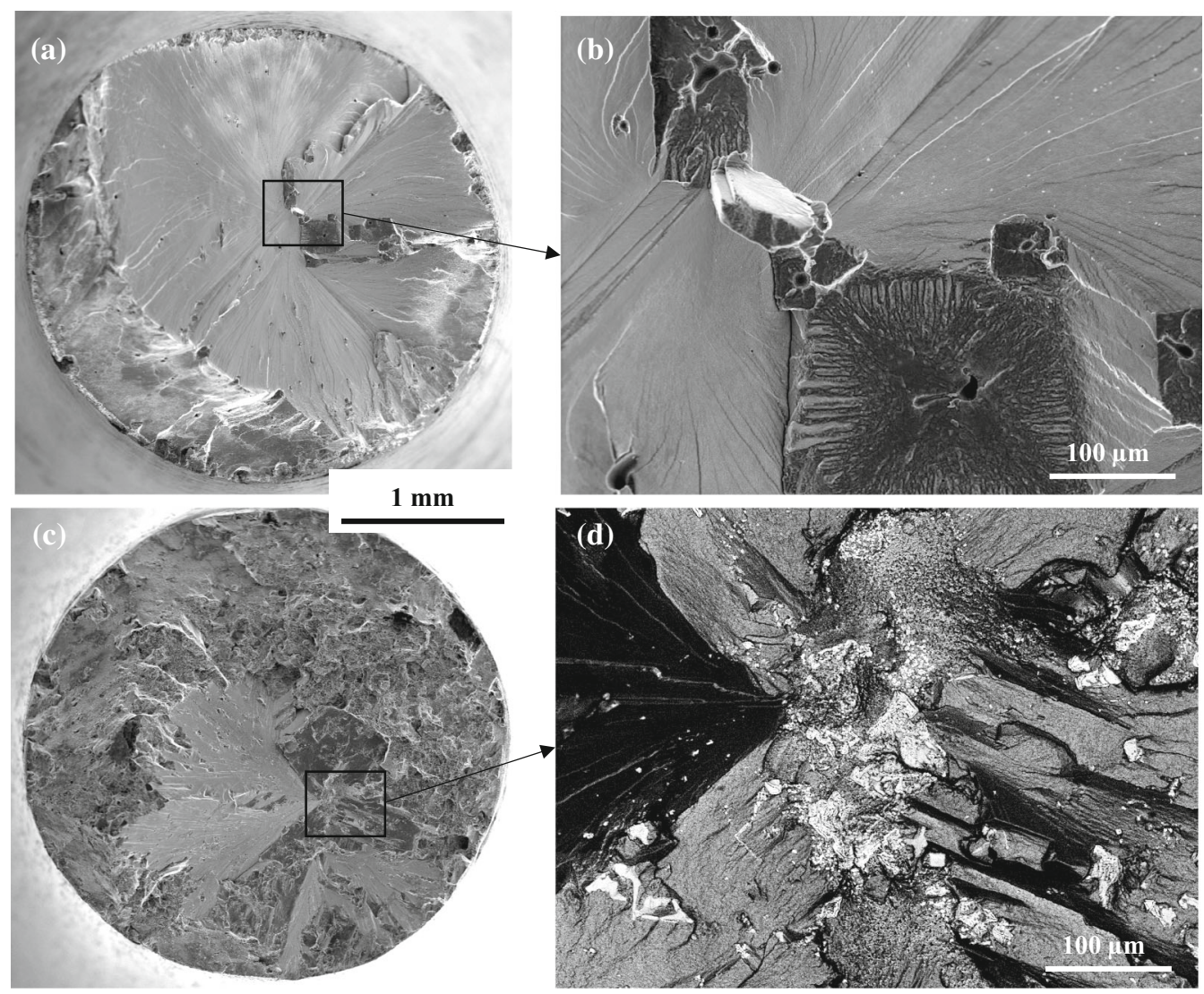

Fig. 8-Rupture surface of CMSX-4 plus specimen tested at $R=0.8, \sigma_{\max }=530 \mathrm{MPa}$, and failed at $N_{\mathrm{f}}=1.1 \times 10^{9}$ cycles $(a)$; magnification of mode I micro-propagation around pores $(b)$; rupture surface of DS200 $\mathrm{Hf}$ specimen tested at $R=0.8, \sigma_{\max }=670 \mathrm{MPa}$, and failed at $N_{\mathrm{f}}=7.9 \times 10^{7}$ cycles $(c)$; magnification of the principal initiation site, constituted of a cluster of carbides (BSE mode) $(d)$.

When porosity is closed by the addition, before and/ or in the meantime of solutionning, of a HIP treatment, VHCF lifetime is highly improved, at least by a factor of ten [see Figure 3(b)]. These observations were already done in the VHCF regime at ambient temperature ${ }^{[39]}$ and the $\mathrm{LCF}$ regime at $750^{\circ} \mathrm{C}$, where it is thought that HIP treatment reduces plastic deformation. ${ }^{[40]}$ Then, other metallurgical defects act as stress concentration sites and will be presented in the next section.

When environment has no strong impact, it is possible to predict VHCF life at $R=-1$ using a crack initiation model. ${ }^{[9,21]}$ This model adapts the fatigue indicator parameter (FIP $)^{[41]}$ that considered the stress intensity factor close to the crack initiation site:

$$
\mathrm{FIP}=\frac{\mu \Delta \sigma}{E}\left[1+k \frac{\Delta K}{\Delta K_{\text {threshold }}}\right] .
$$

In Eq. [1], $\mu$ is the Schmid factor equal to 0.408 for octahedral slip with an applied stress along the [001] direction. $\Delta \sigma$ is the applied positive stress range and $E$ the Young's modulus. Parameter $k$ is taken equal to 1 , and $\Delta K_{\text {threshold }}$ is taken equal to $10 \mathrm{MPa} \mathrm{m} \mathrm{m}^{0.5}$, which is the threshold stress intensity factor of AM1 at $950{ }^{\circ} \mathrm{C}$ in air for long crack propagation. ${ }^{[42]}$ The initial stress intensity factor $K_{\mathrm{I}}$ around the critical pore is calculated with the following equation:

$$
K_{\mathrm{I}}=Y \sigma \sqrt{\pi \sqrt{A_{\text {defect }}}}
$$

$Y$ is equal to 0.5 for internal and to 0.65 for sub-surface initiations. ${ }^{[43]} \sigma$ is the applied positive stress and $A_{\text {defect }}$ the area of the pore measured on the fracture surface from the equivalent diameter method. ${ }^{[21]}$ The FIP has been calculated for all tested materials and for each specimen exhibiting a single internal crack initiation from a pore. The Young's modulus and the highest Schmid factor used to calculate the FIP take into consideration the primary misorientation of each specimen. At $1000{ }^{\circ} \mathrm{C}$, the Young's modulus has been considered equal for all SX and DS alloys investigated. ${ }^{[28-33]}$

Figure 9 presents the FIP calculated as a function of the number of cycles until failure. LCF results from Steuer et al. study on AM1 (Bridgman and LMC) at $750{ }^{\circ} \mathrm{C}^{[21]}$ have been added in the graph, as well as VHCF results from Nie et al. on the DS DZ4 alloy at room temperature. ${ }^{[39]}$ This diagram shows that the FIP values fall onto one single power-law master curve whatever the alloy, temperature, and fatigue regime (i.e., $\mathrm{LCF}$ vs VHCF). This power-law relationship is described in Eq. [3]:

$$
N_{\mathrm{f}}=7.12 \times 10^{-10}(\mathrm{FIP})^{-5.67} \text {. }
$$




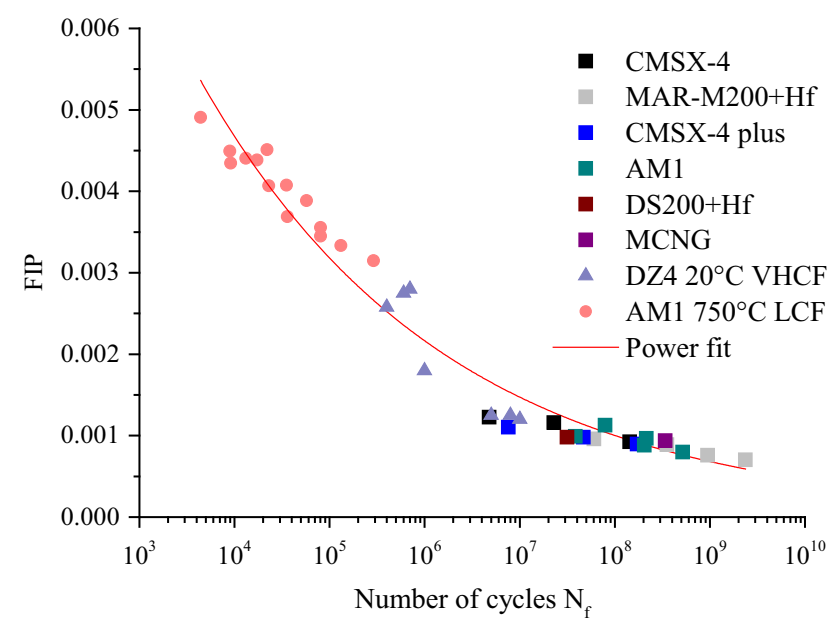

Fig. 9-FIP parameter is plotted as a function of the number of cycles until failure. Results from the literature have been added ${ }^{[21,39]}$ (Color figure online).

Lifetime estimations using this approach show good results as 58 pct of the model estimations is within a factor of two scatter band and 85 pct of the results within a factor of three scatter band. These results on all SX and DS alloys tested (except HIP ones) demonstrate another time that, provided that the temperature dependence of the Young's modulus is taken into account as in Figure 9, the pore size is the dominant factor controlling lifetime between $10^{6}$ and $10^{9}$ cycles. In such conditions, chemical composition or presence of other metallurgical defects have a secondary influence of the fatigue life. Crack initiation (and life) under these fatigue conditions are mainly dependent on the local stress concentration close to the pores and hence, mainly process dependent. ${ }^{[19,20]}$

\section{B. Impact of Defect Nature at $R=-1$}

Both eutectics and carbides are defects that do not present a prominent role on the VHCF life in comparison with pores. Area fraction of eutectics and presence of carbides have not significantly impacted the VHCF lifetime between $10^{6}$ and $10^{9}$ cycles. In addition, it appears that their presence and volume fraction hardly impact the nature and localization of the crack initiation sites in this lifetime range.

It is even more obvious when MAR-M200 + Hf and DS200 + Hf alloys are considered. Both alloys present crack initiation from pores full of small cracked carbides at $20 \mathrm{kHz}, 1000{ }^{\circ} \mathrm{C}$, and $R=-1$, similar to studies done on René N5 in the $\mathrm{LCF}$ regime at $538^{\circ} \mathrm{C}^{[20]}$ and PWA1484 in the $\mathrm{HCF}$ regime at $800{ }^{\circ} \mathrm{C} \cdot{ }^{[19]}$ However, MAR-M200 + Hf is a SX alloy containing much more carbides than these two alloys. At $650^{\circ} \mathrm{C}$ in the LCF regime, crack initiation mainly originates from internal clusters of carbides that can reach a size of up to $200 \mu \mathrm{m} .{ }^{[23]}$ At $900{ }^{\circ} \mathrm{C}$, cracks initiate from sub-surface carbides. Indeed, elevated temperature is sufficient to crack carbides in 5 minutes ${ }^{[44]}$ which then become preferential sites for initiating oxidation-assisted damage. In this study, ultrasonic tests require a 40 minutes stabilization at $1000{ }^{\circ} \mathrm{C}$ before initiating the mechanical solicitation. ${ }^{[9]}$ Then, surface-cracked carbides are expected right from the beginning of the test. Nevertheless, it seems that pores are still more detrimental in terms of crack initiation and have a higher stress concentration potential in this configuration.

When fatigue life exceeds $10^{9}$ cycles, pores are no more the main crack initiation sites. Other metallurgical defects such as eutectics and carbides then might become critical for all SX and DS alloys investigated, leading to a "FGA" crack initiation process as observed in Figure 4(c). These observations are also true for HIPped materials in which pores have been closed. According to past studies, carbides could also be preferential crack initiation sites in $\mathrm{HCF}^{[5]}$ and VHCF regimes ${ }^{[6,7]}$ even if crack initiation from eutectics is possible. ${ }^{[5,45]}$ In our study, HIPped materials do not contain carbides, and then eutectics become the preferential sites.

Moreover, at elevated number of cycles, it seems that crack initiation mechanisms are promoted by the precipitation of intermetallic particles. Figures 10(a) and (b) show SEM observations in BSE observing mode done on a CMSX-4 fracture surface specimen failed at $2.5 \times 10^{9}$ cycles from a eutectic. ${ }^{[9]}$ In the rough area, small bright particles can be observed and are thought to be TCP phases according to previous articles. ${ }^{[46,47]}$ After careful polishing of the fracture surface, particles are found lying along slip bands [see Figures 10(c) and (d)]. Similar observations have already been done after thermal-mechanical fatigue of CMSX-4 by Moverare et al., ${ }^{[48]}$ who observed precipitation of $\mu$-phase, rich in $\mathrm{W}, \mathrm{Ta}$, and Re, in bands of localized deformation, or after pre-straining at room temperature of CMSX-4 specimens in compression and subsequent annealing at $950{ }^{\circ} \mathrm{C} \cdot{ }^{[49]}$

The precipitation kinetics and nature of TCP particles strongly depend on the chemical composition of the alloy, ${ }^{[50]}$ and also on the local chemical composition. Indeed, Kontis et al. have recently shown segregations of chromium and cobalt at dislocations in two superalloys submitted to different mechanical and thermal tests. ${ }^{[51]}$ They argue that a high dislocation density could partially or completely dissolve $\gamma^{\prime}$ precipitates. In our case, it is suspected that the formation of slip bands in the rough area could locally modify the chemical composition of the alloy, and then promote the precipitation of TCP phases due to such preferential segregation of chromium and other elements. Hence, VHCF lives superior to $10^{9}$ cycles might be dependent on the chemical composition of the alloy and on the microstructural features other than pores, increasing fatigue variability. ${ }^{[25,34]}$ However, the nature of these particles need to be checked by EDS and EBSD measurements to know if they are TCP phases. Moreover, crack initiation mechanisms and the rough area formation during VHCF tests need to be clarified. Both aspects will be studied in-depth in a forthcoming paper.

\section{Impact of Oxidation at $R=-1$}

Crack initiation from the surface has not been observed for all SX and DS alloys failed between $10^{6}$ 

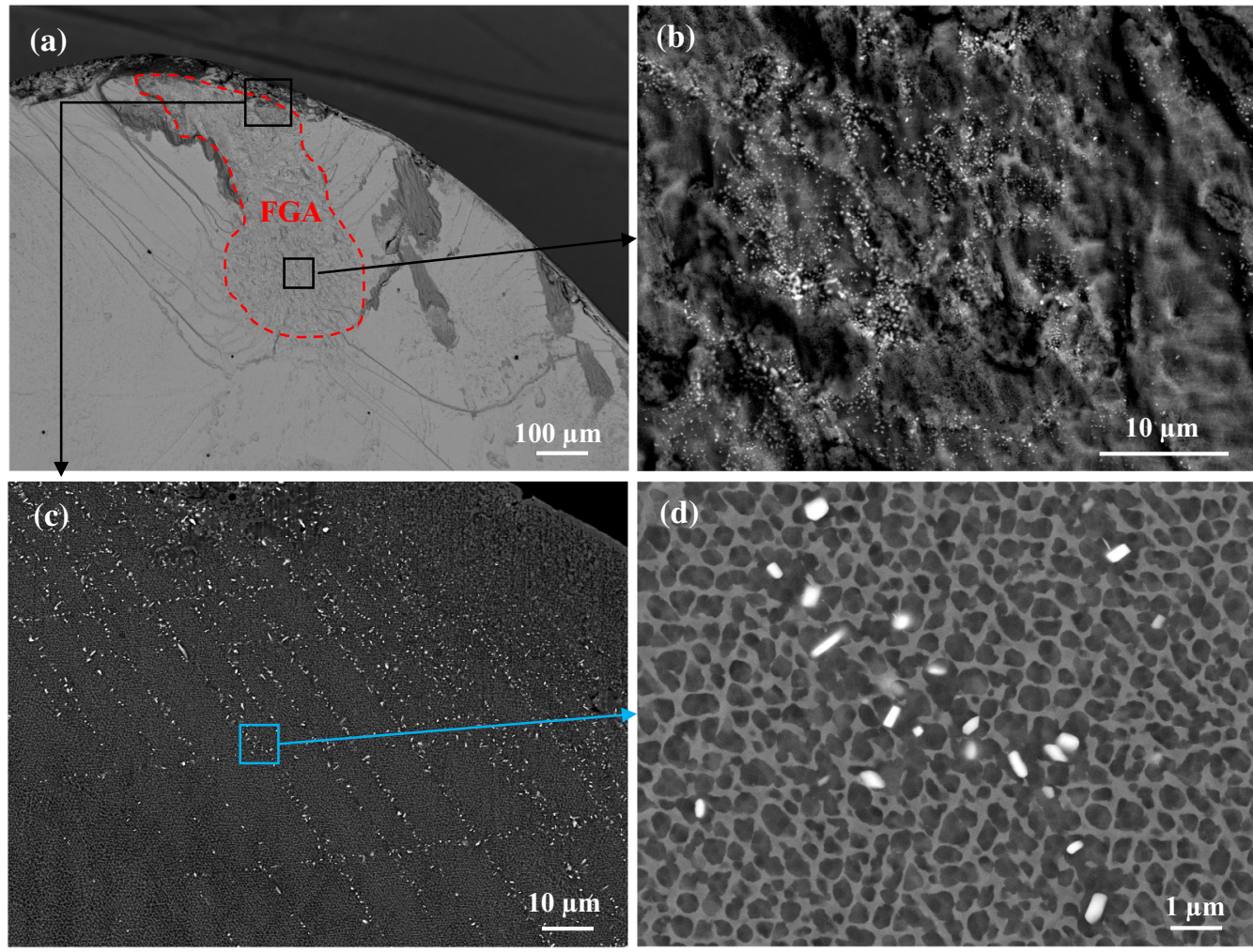

Fig. 10-FGA in fracture surface of a CMSX-4 specimen tested at $\sigma_{\mathrm{a}}=160 \mathrm{MPa}$ and failed at $N_{\mathrm{f}}=2.54 \times 10^{9}$ cycles from a eutectic. Note that the specimen has been oriented to have a flat fracture surface $(a)$; magnification of the rough area (FGA) $(b)$; magnification of the rough area after polishing of the fracture surface $(c)$; magnification of the precipitation of intermetallic particles on slip bands $(d)$. Note that all pictures are in BSE mode.

and $10^{9}$ cycles. Oxidation processes, which are mainly time dependent, ${ }^{[52]}$ have no significant impact before $10^{9}$ cycles (i.e., 14 hours of thermal exposure) in the conditions studied in the VHCF regime. When 14 hours of exposure are exceeded, transition from internal to surface crack initiation has been observed firstly on a DS200 + Hf specimen which is well known for its poor oxidation resistance ${ }^{[14,53]}$ (see Figures 11(a) and 6(c), where several cracks initiated from the surface are visible).

For longer times of exposure, failures caused by mode I cracks propagating from the surface have been observed in HIPped materials (MCNG and AM1, see Figure 5). It seems that a stress concentration competition between internal metallurgical inclusions and mode I cracks from the oxide layer appears during long duration tests. At that level of alternating stress, internal defects have a too low stress concentration to allow faster crack initiation compared to the crack initiation and first stages of propagation from the oxide layer. When these cracks are long enough, they become stress concentration sites and localized deformation at the crack tip in the form of slips bands happens [see Figure 5(d)]. These changes are firstly seen on HIPped materials that do not contain large stress concentration sites as pores. The rate at which mode I cracks propagate as well as the nature of the oxide scale and oxidation kinetics should have an important influence on this transition.
Pre-oxidized CMSX-4 specimens were then used to investigate the competition between stress concentration around defects and the propagation of cracks from the oxide layer. Previous literature ${ }^{[54]}$ have shown that a thermal pre-exposure at $982{ }^{\circ} \mathrm{C}$ during 100 hours on a DS superalloy reduces considerably the LCF lifetimes due to oxide spallation and change of damage initiation sites from the specimen bulk to the surface. In the VHCF regime and in the conditions studied, it appears that 100 hours of pre-oxidation at $1000{ }^{\circ} \mathrm{C}$ is not sufficient to affect VHCF lifetimes and to induce a change from internal to surface crack initiation. Moreover, oxidation damage is less pronounced (number of crack from the surface and oxide layer depth) on pre-oxidized specimens. Figures 11(b) and (c) compare the gage length of reference and pre-exposed (100 hours) specimens after test. In both cases, internal fatal crack initiation is obtained but it is noticed that the pre-exposed specimen presents less cracks at the surface compared to the reference one. It seems that static oxidation (i.e., thermal pre-exposition at $1000{ }^{\circ} \mathrm{C}$ during 100 hours) has formed a non-porous and adherent oxide layer of $\mathrm{Al}_{2} \mathrm{O}_{3}{ }^{[55,56]}$ that is more difficult to crack. Oxide layer in the reference specimen is formed in the meantime of the VHCF solicitation. It is possible that the alternating stress affects the formation of a dense oxide scale, inducing easier oxide spallation and crack initiation from the oxide layer. More tests at lower stresses $\left(\sigma_{\mathrm{a}}=145\right.$ to $\left.150 \mathrm{MPa}\right)$ should be done in order 

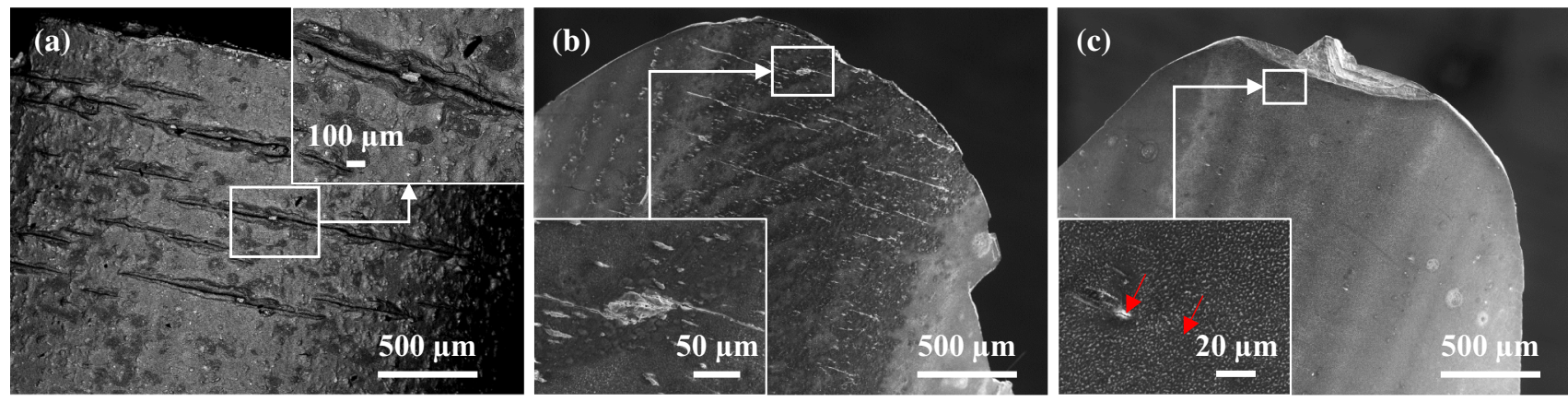

Fig. 11-Cracks initiating from the surface on the gage length of specimens: DS200 + Hf alloy tested at $\sigma_{\mathrm{a}}=145 \mathrm{MPa}$ and failed at $N_{\mathrm{f}}=1.88 \times 10^{9}$ cycles. Carbides highlighted in white are visible between crack lips (BSE mode) (a); CMSX-4 tested at $\sigma_{\mathrm{a}}=160 \mathrm{MPa}$ and failed at $N_{\mathrm{f}}=2.54 \times 10^{9}$ cycles $(b)$; pre-oxidized CMSX-4 at $1000^{\circ} \mathrm{C}$ during $100 \mathrm{~h}$, tested at $\sigma_{\mathrm{a}}=160 \mathrm{MPa}$ and failed at $N_{\mathrm{f}}=1.15 \times 10^{9}$ cycles $(c)$. One has to notice that the magnifications have not the same scale.

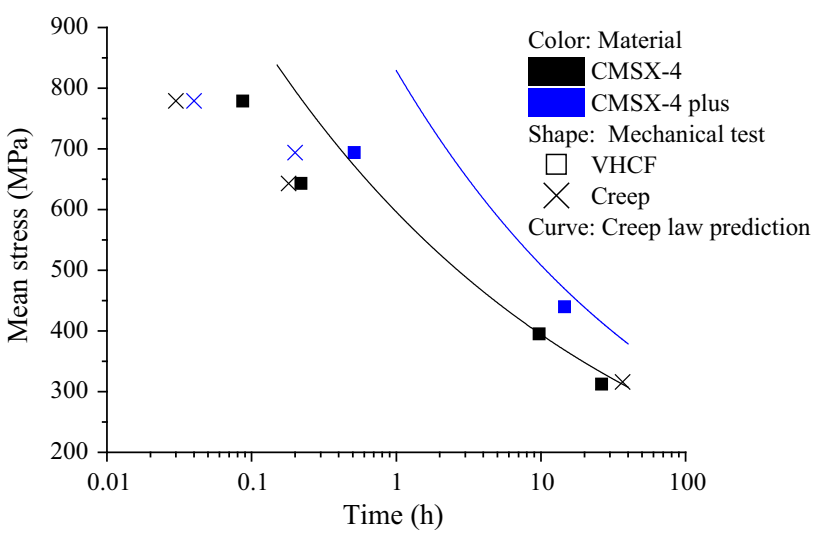

Fig. 12-Comparison of experimental VHCF lifetimes at $R=0.8$ of CMSX-4 and CMSX-4 plus with life predictions from creep law. Crosses (dark and blue for CMSX-4 and CMSX-4 plus, respectively) are results from creep tests done at the same mean stress as the VHCF tests (Color figure online).

to exacerbate oxidation damage and enable to observe different rupture modes. Thermal pre-exposition on SX alloys that do not form adherent oxide scales (i.e., MAR-M200 + Hf, ${ }^{[57]}$ RR3000 ${ }^{[56]}$ ) could also help to observe the competition between internal and surface initiations.

Finally, oxidizing environment also affects crack propagation path. The impact has been noticed on specimens that developed cracks from the surface (HIP AM1 and MCNG) and on alloys that are very sensitive to oxidation (MAR-M200+ Hf and DS200+ Hf). In both cases, their mixed modes fracture surfaces [crystallographic and mode I, see Figures 5(a) and 6(c)] are contrasting with the highly crystallographic fracture surfaces [see Figure 6(a)] commonly observed at $20 \mathrm{kHz}$ on Ni-based SX superalloys. ${ }^{[6,7,9]}$ For SX alloys that develop crack initiation from the surface, Figure 5(d) illustrates well the rupture mechanisms that are activated. When the final failure occurs after such duration test ( 70 hours), mode I cracks are well developed all around the specimen section. Macroscopic crack follows then crystallographic plans, where a crack tip has localized deformation, but is also deviated by several mode I oxidized cracks. In the case of high oxidation sensitive SX alloys, oxidized mode I cracks also affect final crack path even when crack initiation comes from an internal defect.

\section{Impact of Creep Damage at $R=0.8$}

Contrary to what is found at $R=-1$, results at $R=0.8$ show different VHCF lifetimes for a same casting process. Previous work from the authors have shown the prominent role of creep damage on the VHCF lifetime, and then a microstructural sensitivity of the VHCF life when a positive mean stress is superimposed. An impact of the chemical composition was also expected, which is confirmed in Figure 7.

CMSX-4 plus alloy has been developed to improve creep properties over CMSX-4 and first-generation Ni-based SX alloys. ${ }^{[16]}$ Figure 7 shows that CMSX-4 plus has better VHCF life for the same conditions in comparison with CMSX-4 and DS200 + Hf. Conversely, DS200 + Hf alloy has the lowest VHCF durability due to two main reasons. Firstly, it is known that SX alloys have better creep properties than DS alloys with the same chemical composition. ${ }^{[22]}$ Moreover, the SX version MAR-M200 + Hf is a first-generation Ni-based SX superalloy without rhenium (Re, see Table II) which is an element known to improve creep properties by retarding $\gamma^{\prime}$ rafting and strengthening the matrix. ${ }^{[58,59]}$

Creep damage in the fracture surfaces of VHCF specimens is characterized by the occurrence of mode I cracks that have initiated and propagated from pores for all materials tested. For DS200+ Hf alloy, mode I cracks have also initiated from internal clusters of carbides [see Figure 8(b)] and at the sub-surface of the specimens. It is interesting to note that with the addition of a high mean stress, carbides play a role on the failure mechanisms, as it is usually found during LCF and creep tests at high temperature. ${ }^{[23]}$ Bathias and Paris ${ }^{[25]}$ had already noted the prominent role of pores at $R$ ratios close to -1 that could hide the role of inclusions. When $R$ ratios is close to 1 , inclusions then become the main VHCF life-controlling parameters.

Finally, if creep is considered as the main damage mechanism involved during VHCF at $R=0.8$ and 
$1000{ }^{\circ} \mathrm{C}, \mathrm{VHCF}$ lifetimes are more related to a time to rupture than to a number of cycles to failure. Figure 12 points out the time dependence of VHCF lifetimes at $R=0.8$ due to creep damage. In this plot, $\mathrm{VHCF}$ lifetimes of CMSX-4 and CMSX-4 plus are compared with predicted lifetimes computed from time to rupture creep laws. Using a Rabotnov-Kachanov law, time to rupture has been determined according to Eq. [4]:

$$
t_{\mathrm{r}}=\frac{1}{r+1}\left[\frac{\sigma_{0}}{A_{0}}\right]^{-r},
$$

where $t_{\mathrm{r}}$ is the time to rupture in hours and $\sigma_{0}$ the mean stress $\left(\sigma_{\mathrm{m}}\right)$ applied during the VHCF test. $A_{0}$ and $r$ are material constants characterized at $1000{ }^{\circ} \mathrm{C}$ by Safran Helicopter Engines for CMSX-4, and Safran Tech for CMSX-4 plus.

Figure 12 shows that for a number of cycles close to $10^{9}$ cycles (14 hours), a time to rupture creep law enables to predict VHCF lifetime at $R=0.8$ and $1000{ }^{\circ} \mathrm{C}$ with quite a good precision (predictions within a factor 1.3). However, at higher mean stresses (duration tests $<30$ minutes), VHCF lifetime predictions are over-estimated in both materials. Indeed, materials constant ( $A_{0}$ and $r$ ) of the Rabotnov-Kachanov law are not characterized for so short-duration tests and high stresses. Three isothermal creep tests at $1000{ }^{\circ} \mathrm{C}$ have been performed at the mean stress of short $\mathrm{VHCF}$ duration tests to compare lifetimes with VHCF tests and predicted results. Times to failure, represented by crosses in Figure 12, are in agreement with short-duration VHCF tests. Hence, VHCF lifetimes at such high mean stresses cannot be predicted in a satisfying way from a Rabotnov-Kachanov law (Eq. [4]) whose materials parameters $\left(r\right.$ and $A_{0}$ ) have been identified from a set of creep tests performed at low applied stresses, even if creep is the main damage. A change in the creep life sensitivity to the applied stress probably exists at high applied stresses, resulting from, e.g., a change in rate-controlling deformation mechanisms, as suggested recently in the case of creep properties of AD730 alloy at $700{ }^{\circ} \mathrm{C}$. ${ }^{[60]}$

\section{CONCLUSIONS}

VHCF properties at high temperature $\left(1000{ }^{\circ} \mathrm{C}\right)$ of Ni-based SX and DS superalloys have been investigated using an ultrasonic fatigue machine $(20 \mathrm{kHz})$. The roles of the pore size, presence of microstructural features (eutectics, carbides), and oxidation on the VHCF lifetime and failure modes have been studied under fully reversed conditions. By adding a high mean stress ( $R=0.8)$, the impact of the creep behavior of three alloys (two SX and one DS alloys) has been investigated. From this work, the main conclusions are:

- Casting pore size is the main factor controlling VHCF lifetime at $R=-1,20 \mathrm{kHz}$, and $1000{ }^{\circ} \mathrm{C}$, whatever the volume fraction of others defects. Reduction of pore size or porosity closure by HIP treatment can increase up to a factor $20 \mathrm{VHCF}$ lifetimes. The elaboration processes (solidification and prior HIP treatment) have then a prominent contribution to the VHCF life compared to the chemical composition. In these conditions, VHCF lifetimes can be estimated for all SX/DS alloys using a crack initiation model that uses the pore size.

- For lifetimes approaching $10^{9}$ cycles or when porosity is absent, nature of the initiation site switches to other microstructural features (in this study, eutectics). The formation of intermetallic particles along slip bands, thought to be TCP phases, has been observed around the internal crack initiation site and need complementary characterizations to conclude on their impact on crack initiation mechanisms. This will be discussed in a forthcoming paper that will be focused on crack initiation mechanisms and the formation of the rough area (assimilated to the FGA observed during VHCF tests on high-strength steels) around the main crack initiation site.

- At longer duration tests, oxidation damage affects the crack initiation stage by concentrating stress at mode I cracks tips. Transition from internal to surface initiation site depends on the ability of each SX alloy to form a continuous and adherent oxide scale.

- When creep damage is the factor controlling lifetime ( $R \geq 0.8)$, SX alloys developed to have better creep properties have the best VHCF lifetimes. In this case, VHCF lifetimes can be estimated using a time to rupture creep law specifically identified for each SX alloy.

\section{ACKNOWLEDGMENTS}

Safran Helicopter Engines is acknowledged for its financial and scientific support. Safran Tech, Safran Aircraft Engines, and UCSB are acknowledged for providing material. Pr. T. Pollock is thanked for fruitful suggestions in this work. D. Marchand (Institut Pprime) is acknowledged for his decisive contribution in the development of the ultrasonic fatigue machine, and Dr. L. Mataveli-Suave (Safran Tech) for her great interest in the present study. Special thanks to $\mathbf{J}$. Lefort, L. Jouvanneau, T. Delage, and F. Leproux (Institut Pprime) for their contributions.

\section{REFERENCES}

1. T.J. Carter: Eng. Fail. Anal., 2005, vol. 12, pp. 237-47.

2. N. Matan, D.C. Cox, P. Carter, M.A. Rist, C.M.F. Rae, and R.C. Reed: Acta Mater., 1999, vol. 47, pp. 1549-63.

3. V. Brien and B. Décamps: Mater. Sci. Eng. A, 2001, vol. 316, pp. 18-31.

4. B.A. Cowles: Int. J. Fract., 1996, vol. 80, pp. 147-63.

5. P.K. Wright, M. Jain, and D. Cameron: Superalloys-2004, 2004, pp. 657-66.

6. R.J. Morrissey and P.J. Golden: Int. J. Fatigue, 2007, vol. 29, pp. 2079-84.

7. J.Z. Yi, C.J. Torbet, Q. Feng, T.M. Pollock, and J.W. Jones: Mater. Sci. Eng. A, 2007, vol. 443, pp. 142-49. 
8. Y. Furuya, K. Kobayashi, M. Hayakawa, M. Sakamoto, Y. Koizumi, and H. Harada: Mater. Lett., 2012, vol. 69, pp. 1-3.

9. A. Cervellon, J. Cormier, F. Mauget, and Z. Hervier: Int. J. Fatigue, 2017, vol. 104, pp. 251-62.

10. P. Caron and T. Khan: Mater. Sci. Eng., 1983, vol. 61, pp. 173-84.

11. T. Murakumo, T. Kobayashi, Y. Koizumi, and H. Harada: Acta Mater., 2004, vol. 52, pp. 3737-44.

12. B. Ruttert, D. Bürger, L.M. Roncery, A.B. Parsa, P. Wollgramm, G. Eggeler, and W. Theisen: Mater. Des., 2017, vol. 134, pp. 418-25.

13. C.L. Brundidge, D. van Drasek, B. Wang, and T.M. Pollock: Metall. Mater. Trans. A, 2012, vol. 43A, pp. 965-76.

14. L. Mataveli Suave, J. Cormier, P. Villechaise, D. Bertheau, G. Benoit, G. Cailletaud, and L. Marcin: Mater. High Temp., 2016, vol. 33, pp. 361-71.

15. J.L. Smialek: J. Eng. Gas Turbines Power, 1998, vol. 120, pp. $370-74$.

16. J.B. Wahl and K. Harris: Superalloys, 2016, vol. 2016, pp. 25-33.

17. R.C. Reed: The Superalloys: Fundamentals and Applications, Cambridge University Press, Cambridge, 2008.

18. T. Khan and P. Caron: Mater. Sci. Technol., 1986, vol. 2, pp. 486-92.

19. M. Lamm and R.F. Singer: Metall. Mater. Trans. A, 2007, vol. 38A, pp. 1177-83.

20. C. Brundidge and T.M. Pollock: Superalloys, 2012, vol. 2012, pp. 369-77.

21. S. Steuer, P. Villechaise, T.M. Pollock, and J. Cormier: Mater. Sci. Eng. A, 2015, vol. 645, pp. 109-15.

22. T.M. Pollock and S. Tin: J. Propuls. Power, 2006, vol. 22, pp. 361-74.

23. L. Mataveli Suave: High Temperature Damage Mechanisms in DS200 + Hf Alloy. Ph.D. Dissertation, ENSMA, 2017.

24. H. Mayer: Int. Mater. Rev., 1999, vol. 44, pp. 1-34.

25. C. Bathias and P.C. Paris: Int. J. Fatigue, 2010, vol. 32, pp. 894-97.

26. S. Stanzl-Tschegg: Int. J. Fatigue, 2014, vol. 60, pp. 2-17.

27. H. Mayer: Fatigue Fract. Eng. Mater. Struct., 2016, vol. 39, pp. 3-29.

28. H.-A. Kuhn and H.G. Sockel: Phys. Status Solidi, 1990, vol. 119, pp. 93-105.

29. P. Mazot and J. de Fouquet: Mém. Etudes Sci. Rev. Métall., 1992, pp. $165-70$.

30. A. de Bussac and P. Poubanne: Loi de Comportement Anisotrope de l'AM1 de $20^{\circ} \mathrm{C}$ à $1200^{\circ} \mathrm{C}, \mathrm{YKOM1/YLEV} \mathrm{60291,} 1992$.

31. W. Hermann, H.G. Sockel, J. Han, and A. Bertram: in Superalloys 1996, R.D. Kissinger, D.J. Deye, D.L. Anton, A.D. Cetel, M.V. Nathal, T.M. Pollock, and D.A. Woodford, eds., 1996.

32. D. Siebörger, H. Knake, and U. Glatzel: Mater. Sci. Eng. A, 2001, vol. 298, pp. 26-33.

33. R. Giraud: Influence de l'histoire Thermique Sur Les Propriétés Mécaniques à Haute et Très Haute Température Du Superalliage Monocristallin CMSX-4. Ph.D. Dissertation, ENSMA, 2014.

34. R.J. Morrissey, R. John, and W. John Porter: Int. J. Fatigue, 2009, vol. 31, pp. 1758-63.

35. D. Spriestersbach, A. Brodyanski, J. Lösch, M. Kopnarski, and E. Kerscher: Procedia Struct. Integr., 2016, vol. 2, pp. 1101-08.
36. Y.-D. Li, L.-L. Zhang, Y.-H. Fei, X.-Y. Liu, and M.-X. Li: Int. J. Fatigue, 2016, vol. 82, pp. 402-10.

37. S. Heinz and D. Eifler: Int. J. Fatigue, 2016, vol. 93, pp. 301-08.

38. J.K. Tien and R.P. Gamble: Metall. Trans., 1971, vol. 2, pp. 1933-38.

39. B. Nie, Z. Zhao, S. Liu, D. Chen, Y. Ouyang, Z. Hu, T. Fan, and H. Sun: Materials, 2018, vol. 11, p. 98.

40. C. Zhang, W. Hu, Z. Wen, H. Zhang, and Z. Yue: J. Alloys Compd., 2016, vol. 655, pp. 114-23.

41. A. Fatemi and N. Shamsaei: Int. J. Fatigue, 2011, vol. 33, pp. $948-58$.

42. M. Geuffrard: Amorçage et micro-propagation de fissure en fatigue à haute température à partir de défauts dans un superalliage monocristallin. Ph.D. Dissertation, Ecole Nationale Supérieure des Mines de Paris, Paris, 2010.

43. S. Beretta, A. Blarasin, M. Endo, T. Giunti, and Y. Murakami: Int. J. Fatigue, 1997, vol. 19, pp. 319-33.

44. L. Mataveli Suave, J. Cormier, P. Villechaise, D. Bertheau, G. Benoit, F. Mauget, G. Cailletaud, and L. Marcin: in Superalloys 2016, M. Hardy, E. Huron, U. Glatzel, B. Griffin, B. Lewis, C. Rae, V. Seetharaman, and S. Tin, eds., 2016, pp. 745-56.

45. D.P. DeLuca and C. Annis: Fatigue in Single Crystal Nickel Superalloys, Pratt and Whitney, 1993.

46. K. Cheng, C. Jo, T. Jin, and Z. Hu: Mater. Sci. Eng. A, 2011, vol. 528, pp. 2704-10.

47. B. Dubiel, P. Indyka, I. Kalemba-Rec, A. Kruk, T. Moskalewicz, A. Radziszewska, S. Kąc, A. Kopia, K. Berent, and M. Gajewska: J. Alloys Compd., 2018, vol. 731, pp. 693-703.

48. J.J. Moverare, S. Johansson, and R.C. Reed: Acta Mater., 2009, vol. 57, pp. 2266-76.

49. B.G. Choi, C.Y. Jo, H.U. Hong, I.S. Kim, S.M. Seo, and H.M. Kim: Trans. Nonferrous Met. Soc. China, 2011, vol. 21, pp. 1291-96.

50. T.M. Pollock: Mater. Sci. Eng. B, 1995, vol. 32, pp. 255-66.

51. P. Kontis, Z. Li, D.M. Collins, J. Cormier, D. Raabe, and B. Gault: Scripta Mater., 2018, vol. 145, pp. 76-80.

52. M.H. Li, X.F. Sun, T. Jin, H.R. Guan, and Z.Q. Hu: Oxid. Met., 2003, vol. 60, pp. 195-210.

53. M.G.D. Duhl and A.F. Giamei: in Superalloys 1980, vol. 41, Warrendale, 1980, pp. 205-14.

54. A.P. Gordon, R.W. Neu, and D.L. McDowell: Int. J. Fatigue, 2009, vol. 31, pp. 393-401.

55. M. Göbel, A. Rahmel, and M. Schütze: Oxid. Met., 1993, vol. 39, pp. 231-61.

56. C.M. Younes, G.C. Allen, and J.A. Nicholson: Corros. Eng. Sci. Technol., 2007, vol. 42, pp. 80-88.

57. E. Aghion, M. Bamberger, and A. Berkovits: J. Mater. Sci., 1991, vol. 26, pp. 1873-81.

58. D. Blavette, P. Caron, and T. Khan: Scripta Metall., 1986, vol. 20, pp. 1395-1400.

59. M. Pröbstle, S. Neumeier, P. Feldner, R. Rettig, H.E. Helmer, R.F. Singer, and M. Göken: Mater. Sci. Eng. A, 2016, vol. 676, pp. 411-20.

60. L. Thébaud, P. Villechaise, J. Cormier, C. Crozet, A. Devaux, D. Béchet, J.-M. Franchet, A. Organista, and F. Hamon: Metals, 2015, vol. 5, pp. 2236-51. 